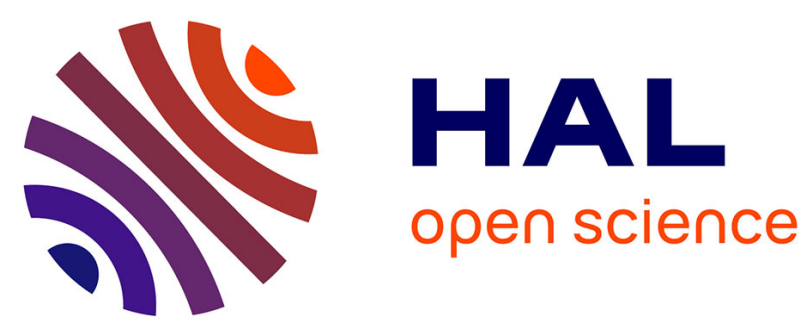

\title{
Modelling anisotropic damage and permeability of mortar under dynamic loads
}

Wen Chen, Olivier Maurel, Thierry Reess, Mohammed Matallah, Antoine de Ferron, Christian La Borderie, Gilles Pijaudier-Cabot

\section{- To cite this version:}

Wen Chen, Olivier Maurel, Thierry Reess, Mohammed Matallah, Antoine de Ferron, et al.. Modelling anisotropic damage and permeability of mortar under dynamic loads. European Journal of Environmental and Civil Engineering, 2011, 15 (5), pp.727-742. 10.1080/19648189.2011.9693361. hal-00683943

\section{HAL Id: hal-00683943 \\ https://hal.science/hal-00683943}

Submitted on 30 Mar 2012

HAL is a multi-disciplinary open access archive for the deposit and dissemination of scientific research documents, whether they are published or not. The documents may come from teaching and research institutions in France or abroad, or from public or private research centers.
L'archive ouverte pluridisciplinaire $\mathbf{H A L}$, est destinée au dépôt et à la diffusion de documents scientifiques de niveau recherche, publiés ou non, émanant des établissements d'enseignement et de recherche français ou étrangers, des laboratoires publics ou privés. 


\title{
Modelling anisotropic damage and permeability of mortar under dynamic loads
}

\author{
Wen Chen* - Olivier Maurel* — Thierry Reess** \\ Mohammed Matallah**** - Antoine De Ferron** \\ Christian La Borderie* — Gilles Pijaudier-Cabot***
}

\author{
* Laboratoire de Sciences Appliquées au Génie Civil et Côtier (LaSAGEC ${ }^{2}$ ) \\ Université de Pau, Allée du Parc Montaury, F-64600 Anglet, France \\ ** Laboratoire de Génie Electrique, Université de Pau, Hélioparc Pau-Pyrénées \\ 2, avenue du Président Angot, F-64053 Pau cedex, France \\ *** Laboratoire des Fluides Complexes, Université de Pau \\ BP 1155, F-64013 Pau cedex, France
}
**** RISAM (RISk Assesment \& Management), Université de Tlemcen BP230, Algérie

\begin{abstract}
This paper deals with the development of a model for concrete subjected to dynamic loads. Shock waves are generated by Pulsed Arc Electro-hydraulic Discharges (PAED) in water and applied to mortar samples. A diphasic model (liquid water and vapour) is implemented in order to describe the electrical discharge and the propagation of shock waves in water. An anisotropic damage model is devised, which takes account of the strain rate effect and the crack closure effect. Coupling between anisotropic damage and permeability is proposed in order to assess the variation of material permeability due to shock waves. Comparisons with experiments show a good correlation between the experimental and the numerical results.
\end{abstract}

RÉSUMÉ. Cette étude porte sur développement d'un modèle du béton sous chargement dynamique rapide. Le chargement dynamique est généré par des ondes de chocs dues à la décharge électrohydraulique d'un arc (PAED) sous l'eau. Un modèle actuel diphasique est qualifié et utilisé pour simuler la décharge électrique et la propagation des ondes dans l'eau. Un modèle d'endommagement anisotrope est développé qui prend en compte l'effet de vitesse de la déformation et la refermeture des fissures. Un couplage entre l'endommagement et la perméabilité anisotropique est proposé. Après la comparaison avec l'expérimentation, une bonne corrélation est observée entre les résultats expérimentaux et numériques.

KEYWORDS: microstructure, permeability, damage, cracking, mortar.

MOTS-CLÉS : microstructure, perméabilité, endommagement, fissuration, mortier. 


\section{Introduction}

The mechanical behaviour of quasi-brittle materials like mortar depends quite strongly on the rate of loading (Abrams 1917; Birkimer et al., 1971). The evolution of microstructure due to such mechanical loads may be characterized by the variation of permeability and the variation of stiffness (material damage). The relationship between static applied loads, the material permeability and damage has been investigated in the past by theoretical and experimental studies (Kermani, 1991; Hearn et al., 1998; Choinska et al., 2007). The rate of loading effect on the microstructure and material damage, in connection with the material permeability remains, however, to be investigated. Micro-cracks generated by dynamic loads are more distributed (less localized) compared to statics (Cao et al., 2001a; Cao et al., 2001b). Given a load level, the variation of permeability is expected to be different in statics and in dynamics. The purpose of the present study is to focus on a specific type of dynamic loads and to discuss numerical models for the description of damage and permeability.

In this study, the dynamic load is a compressive shock wave with an amplitude that is generated by Pulsed Arc Electrohydraulic Discharges (PAED) (Touya et al., 2006). The wave is generated into water and then transmitted to the immersed specimen (diameter $100 \mathrm{~mm}$, height $125 \mathrm{~mm}$ ). It is characterised by its amplitude in water. An experimental program (Maurel et al., 2010) has already been conducted in order to correlate the evolution of cracking and damage due to dynamic loads with the intrinsic permeability of the material, and with its microstructure. Experimental results are recalled in the Section 2.

Then, the whole experimental process is simulated using a 3D finite element calculation with the Europlexus code. A dysphasic model is used to describe the electric discharge and the propagation of the pressure waves according to simplified assumptions. In this model, water and vapour are folded into a single mixture and energy is released into a small region of liquid water according to a time history which is specified by the experimental conditions. The interface between the fluid and solid meshes is modelled by the FSA algorithm (Fluid Structure ALE), which is based upon the hypothesis of nodal conformity of the fluid and structure meshes along their interface (Casadei et al., 2004; Casadei, 2008).

Several rate-dependent damage models have been proposed in order to describe the strain-rate dependent behaviour of concrete subjected to high dynamic loadings. Pedersen et al. (2008), and Gatuingt and Pijaudier-Cabot (2002) devised viscoplastic damage models for this purpose. These isotropic damage-based models did not account for the crack closure effect. Dubé et al. (1996) proposed a constitutive relation which includes the effect of crack closure but still rely on an isotropic description of damage. Anisotropic damage models are also available. The present work starts from the model developed by Desmorat et al. (2007) in which damage is orthotropic, with three principal directions and three principal values of damage in this coordinate system $D_{1}, D_{2}, D_{3}$. Chambart modified the model (2009) and 
introduced additional parameters in order to model the evolution of the dynamic strength and the strain rate dependent properties of concrete. Due to the rate dependent effect, failure due to localization of strain and damage is described in a consistent theoretical way, but the fracture parameters, however, are controlled by the rate dependent properties solely and this may provide some bias on the fracture energy, in statics especially. In the present paper, an additional regularization scheme based upon the variation of fracture energy with element size is introduced in order to recover correct fracture properties in statics, independently from any rate effect. The new constitutive model describes anisotropic cracking and damage, the crack closure effect, strain rate effects and the variation of fracture energy with mesh element size. In addition, a permeability tensor is derived from the damage tensor, and the mechanical model is coupled with a mass transport model, i.e. a simple Darcy like description of fluid flow in damaged concrete. Section 3 discusses the numerical model and comparisons with experimental data are provided in Section 4.

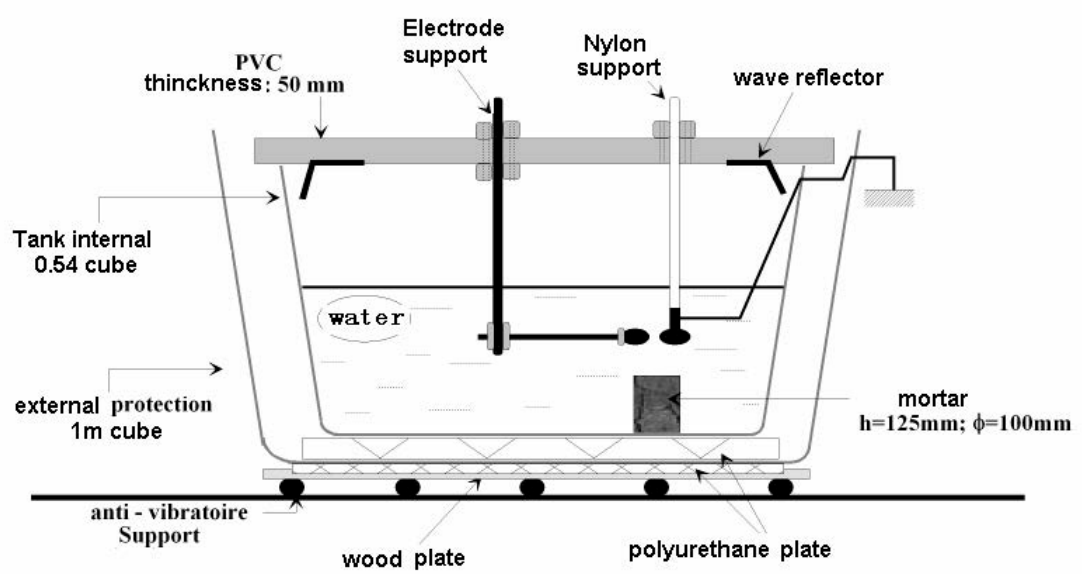

Figure 1. Experimental set-up for PAED on mortar samples

\section{Description of the experimental program}

The PAED method (Pulsed Arc Electrohydraulic Discharges) has been used to generate dynamic underwater shock waves impacting mortar samples (Figure 1). The details of this method and the experimental device have been discussed in Touya (2003), Touya et al. (2006) and Maurel et al. (2010). Hence, we will only provide a short overview of the experimental set-up here.

In this experimental program, the pressure compression wave is generated by PAED in water and then transmitted on one face of a cylindrical mortar specimen. The wave propagates in the specimen and generates micro-cracking and damage due to extensions induced by the Poisson effect. Thus, mortar cylinders are subjected to dynamic loads of various amplitudes propagating along their principal (longitudinal) axis. 


\subsection{Mortar composition and specimen characterisation}

The mortar was made with a maximal grain size of $2 \mathrm{~mm}$ and with a water cement ratio equal to 0.6. Average mechanical properties of mortar are detailed in table 1. Cylindrical test specimens (diameter $100 \mathrm{~mm}$, height $125 \mathrm{~mm}$ ) have been cast in plastic moulds. The characteristics of mortar were obtained from compression and splitting tests on six specimens of the same size. The pure tensile strength is supposed to be $16 \%$ lower that the value obtained from splitting tests.

Table 1. Average mechanical properties of mortar

\begin{tabular}{|c|c|c|c|}
\hline $\mathrm{f}_{\mathrm{c} 28}(\mathrm{MPa})$ & $\mathrm{f}_{\mathrm{t}}(\mathrm{MPa})$ & $\mathrm{E}_{\mathrm{c}}(\mathrm{MPa})$ & $\mathrm{K}_{\mathrm{v}}\left(\mathrm{m}^{2}\right)$ \\
\hline 19.6 & 2.5 & 17300 & $4.10-17$ \\
\hline
\end{tabular}

\subsection{Measurement of permeability to nitrogen}

The measurement of permeability was carried out on cylindrical specimens (100 $\mathrm{mm}$ diameter and $50 \mathrm{~mm}$ height) sawn from tested mortar cylinders. The apparent permeability of the specimen to nitrogen was measured in the direction of the applied compressive waves, by imposing different pressures gradient on the faces of the cylindrical specimens and by measuring the resulting fluid flow. The intrinsic permeability of the specimens was obtained according to the Klinkenberg model. The initial permeability of the material, averaged over 5 specimens, is $4.10^{-17} \mathrm{~m}^{2}$ which is used as reference in forthcoming results to define the initial state of microstructure. The evolution of damage in the specimen is characterized by the variation of permeability measured after the dynamic loading.

\subsection{Test results}

Two test series have been carried out in order to observe the influence of the pressure level and of the number of shock waves applied to the specimens. In the first series, mortar specimens have been subjected to a single shock wave with a variable pressure amplitude. The variations of measured permeability with peak pressure are plotted in Figure 2a. In the second one the amplitude of the shock wave was kept constant $(90 \mathrm{MPa})$, and several different numbers of applied waves were considered. The evolution of the permeability with the number of shocks is plotted in Figure $2 b$.

X-ray tomography (CT scans, microscan) and Mercury intrusion porosimetry (MIP) have been used in order to characterize and to visualize the evolutions of the microstructure of mortar upon the application of shock waves. These results have 
been detailed in (Maurel et al., 2010). In the next section, we will turn to numerical modelling of this experimental set-up and start with the description of the electrical discharge and the subsequent shock wave generated in water, prior it reaches the specimen.

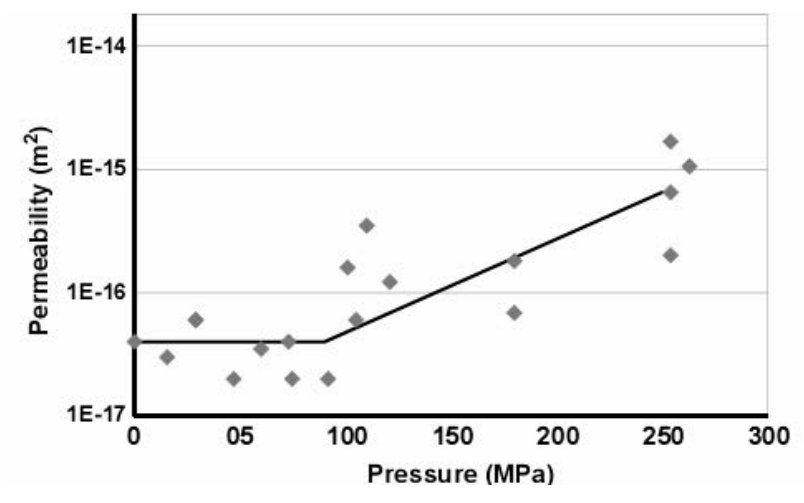

a)

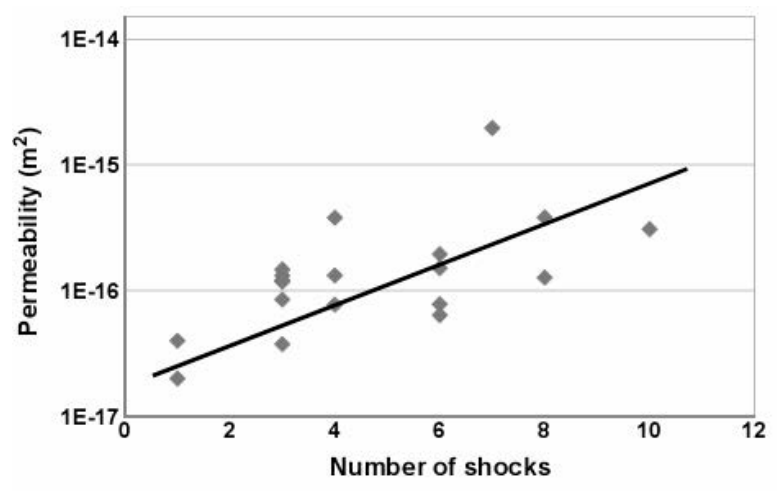

b)

Figure 2. Evolution of permeability a) with applied pressure b) with the number of shocks under a peak pressure equal to $90 \mathrm{MPa}$

\section{Qualification the computer model to simulate PAED}

The underwater electrical discharges is simulated with the diphasic model available in the code EUROPLEXUS. Liquid water and vapour are described by a two-phase mixture, each phase being in thermodynamic equilibrium at the same temperature and pressure. Once the electrical discharge is described, the shock wave travels into water and reaches the solid specimen. The entire set-up (fluid and solid) is modelled with finite element meshes and an ALE description in order to achieve a proper description of the fluid solid interface. This procedure is rather classical in the code and we are going to focus on the description of PAED in this section, and later on, on the solid constitutive models, which are original.

\subsection{Diphasic model in EUROPLEXUS}

The dynamic computer code EUROPLEXUS has been co-developed by CEA (CEN Saclay, DMT) and EC (JRC-Ispra, ISIS) since 1999. This code is based on the Finite Element Method and uses an explicit time integration algorithm (Robbe et al., $2003,2004,2005)$. At each time step, the conservation of mass, the conservation of energy, the state laws, and the conservation of momentum are computed successively. The thermodynamic properties of liquid and vapour follow from tabulated values. Each finite element has a single gauss point (Serguei et al., 2005), at which these properties are calculated. 
The thermodynamic properties of water are tabulated from two variables: the temperature and the pressure. The liquid and vapor phases are separated by the saturation curve denoted as $\operatorname{Sat}(\mathrm{P}, \mathrm{T})=0$, which is illustrated in Figure 3a. In the case of a liquid-vapor mixture, the saturation curve is followed, i.e. the mixture is in equilibrium if the thermodynamic variables are on the saturation curve (Lepareux, 2000). The mass fraction of vapour $\chi$ is defined (Lepareux, 1994):

$$
\chi=\frac{m_{g}}{m}
$$

where $m_{g}$ is the mass of vapour and $m$ is the total mass of fluid. $\chi$ characterizes the concentration of vapor. When $\chi=1$, the fluid is vapor, when $\chi=0$, the fluid is liquid.

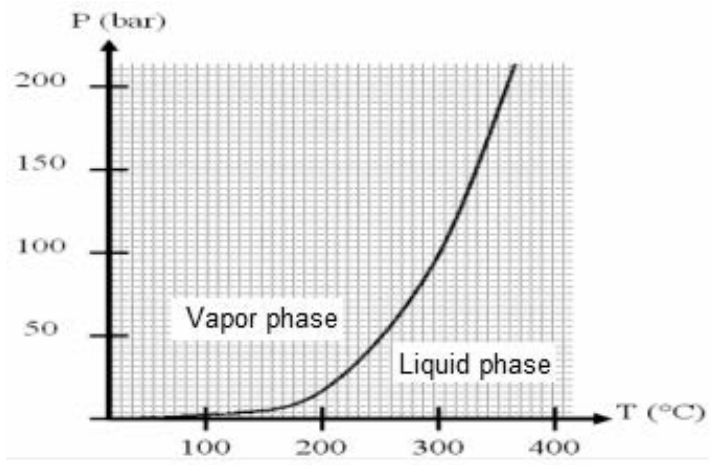

a)

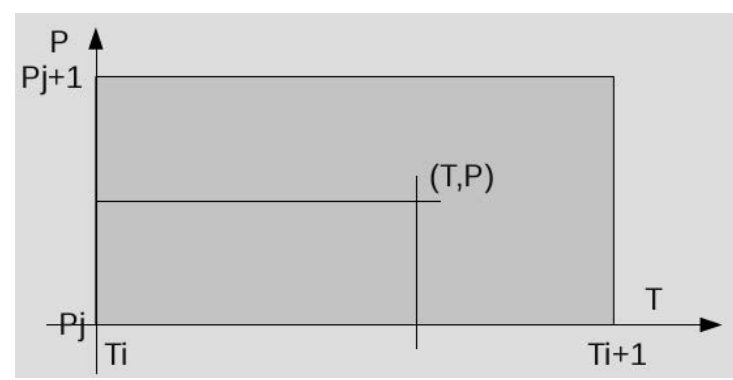

b)

Figure 3. a) saturation curve; b) rectangle interpolation in the water tables

When $0<\chi<1$, the fluid is diphasic, the mass volume $v$ and mass enthalpy $h$ are given by:

$$
\begin{aligned}
& d v=\left(v_{v}-v_{l}\right) d \chi+\left[\chi\left(\frac{\partial v_{v}}{\partial P}\right)_{s a t}+(1-\chi)\left(\frac{\partial v_{l}}{\partial P}\right)_{s a t}\right] d P \\
& d h=\left(h_{v}-h_{l}\right) d \chi+\left[\chi\left(\frac{\partial h_{v}}{\partial P}\right)_{s a t}+(1-\chi)\left(\frac{\partial h_{l}}{\partial P}\right)_{s a t}\right] d P
\end{aligned}
$$

$v_{v}$ and $h_{v}$ are the volume and masse enthalpy of vapor. $v_{l}$ and $h_{l}$ are the volume and masse enthalpy of liquid. To simulate the electrical discharge, electrical energy is injected locally into water as a function of time. The region in which the energy is injected is located between the electrodes. It is the region in which the electrical discharge occurs. The total injected energy in this region can be defined as: 


$$
W=\int_{0}^{\infty} d t \sum_{e=1}^{N} m_{e}^{c} \dot{q}_{e}
$$

where $m_{e}^{c}$ is the mass of water in the element where the energy is injected (assumed to be constant during the application of energy). $\mathrm{N}$ is the number of elements in the area where the energy is applied. The injected mass power in one element $\dot{q}_{e}$ is calculated as follow:

$$
\dot{q}_{e}=\alpha_{m} \times f(t)
$$

Function $f(t)$ describes the evolution of energy injected in the fluid during the discharge, to be defined with time (Figure 4). The coefficient $\alpha_{m}$ is dimensionless and is calibrated from experiments.

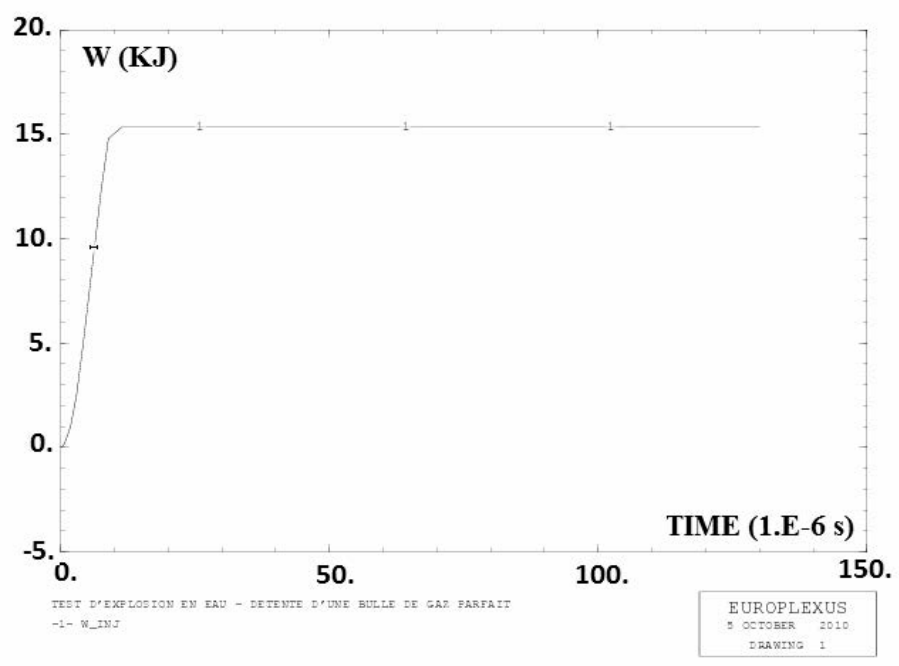

Figure 4. Example of evolution of injected energy with time

\subsection{Calibration of the PAED model}

Several experiments have been carried out with different experimental conditions (injected energy level, distance between the electrodes and the pressure transducer). The pressure wave was recorded with a dynamic transducer located perpendicularly to the inter-electrode space. It is this pressure wave which is compared to the results of computations.

The mesh used in the computations is shown in Figure 5. It is a full Euler-type finite element mesh which represents the fluid nearby the electrodes. The energy is injected locally in the spherical red zone (Figure 5) to simulate the electrical discharge. The diameter of this zone is the distance between the two electrodes. 


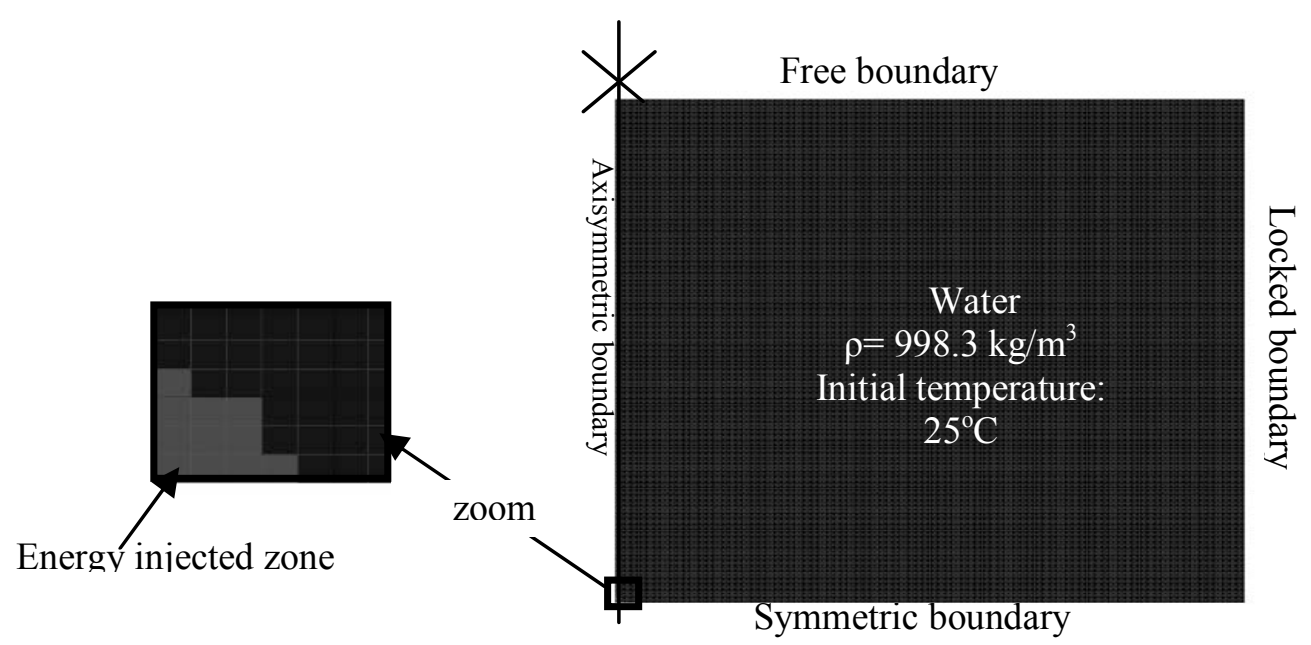

Figure 5. Boundary condition and the numerical mesh of the simulation

The injected energy and distance between the electrodes are the same combination as those used in the experimentation on mortar. Parameters such as the mesh density and the damping constants in the time integration scheme have an influence on the results. These parameters have been set constant, after the calibration between the experimental and measured pressure peaks on a first configuration (energy $=3.3 \mathrm{~kJ}$, distance between the electrodes and the transducer $=17.5 \mathrm{~cm}$ measured along the symmetric boundary in Figure 5). Comparisons between the experimental and numerical results are plotted in Figure 6 for two different configurations.
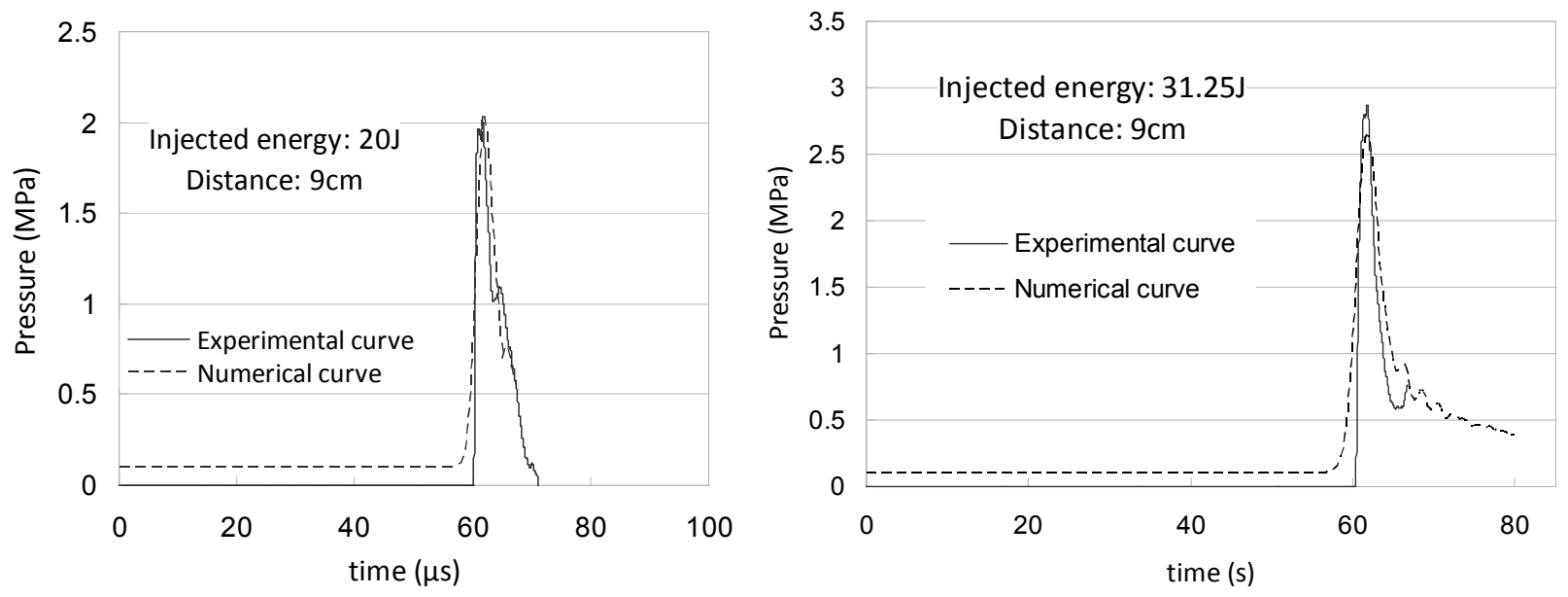

Figure 6. Comparison of the experimental and the numerical pressure 


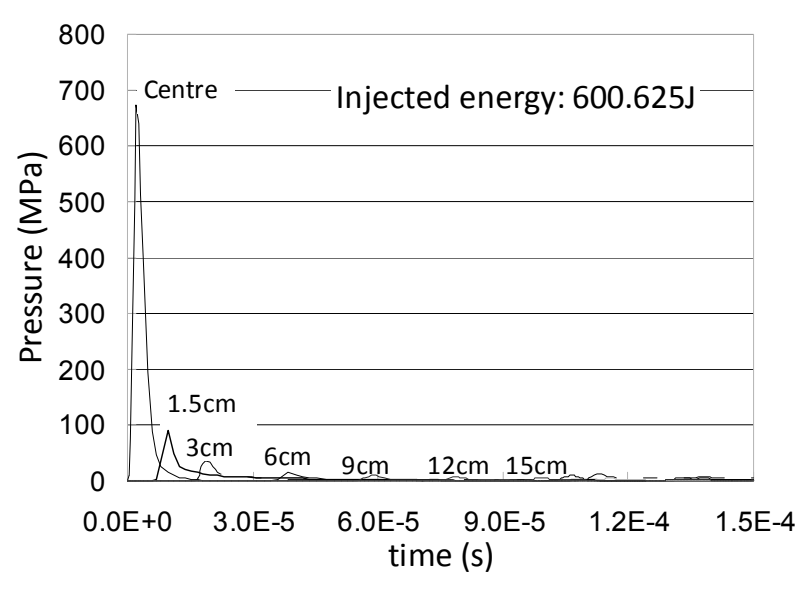

a)

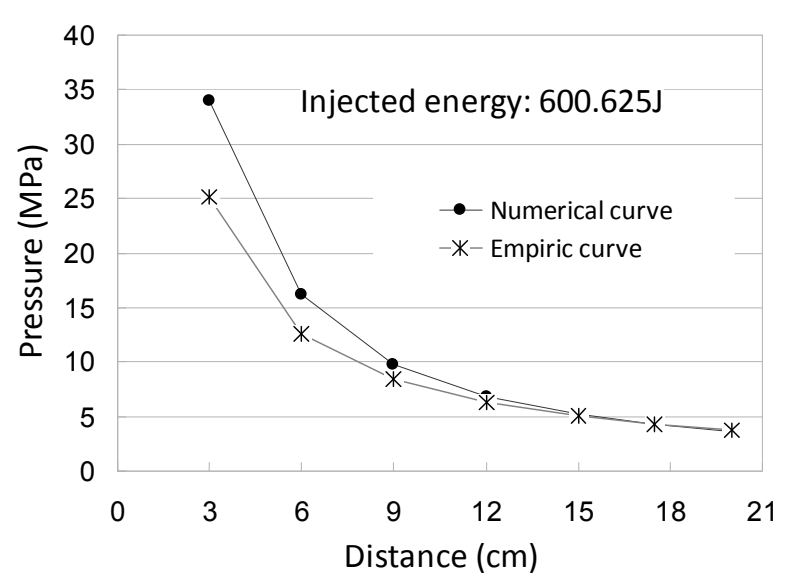

b)

Figure 7. a) propagation of the pressure wave at different distance d; b) comparison the numerical peak pressures relative to the distance $d$ and the empiric formulation

The peak pressure $P_{0}$ may be determined by an empiric formula proposed by Touya et al. (2006) and obtained from experiment datas:

$$
P_{0}=k \cdot E_{B}^{\alpha}
$$

where $E_{B}=1 / 2 . C \cdot U_{B}^{2}\left(U_{B}\right.$ the breakdown voltage value and $C$ is the capacity of the electrical set-up. The parameters $k$ and $\alpha$ depend on the inter-electrode geometry and on the distance $d$ between the pressure transducer and the plasma channel. The amplitude of the pressure wave reduces during the propagation in water (Figure 7a). Figure $7 \mathrm{~b}$ shows the evolution of the peak pressures with the distance between the electrodes and the pressure transducer. The empiric curve, which is fitted by the empirical formula in Equation [6], and the numerical results are quite close to each other. The transducer could not be placed too close to the electrodes because the pressure would damage it, experimental data in this range are extrapolations from Equation [6]. The two curves are increasingly close to each other and superpose for distances larger than $12 \mathrm{~cm}$.

\section{Numerical modelling of the experiments on mortar}

The entire experimental process is described numerically with three models: fluid and solid finite element meshes with the FSA algorithm for the interface between the two, a diphasic model for water, and the $3 \mathrm{D}$ anisotropic model for mortar. The anisotropic numerical permeability of the damaged specimen has been also introduced. This section describes the constitutive models for mortar. Comparisons with PAED experiments are discussed. 


\subsection{Anisotropic rate-dependent damage model}

The model is based on the rate-independent anisotropic damage model proposed by (Desmorat et al., 2007). The model introduces an effective stress denoted as $\widetilde{\sigma}$ defined by:

$$
\widetilde{\sigma}=\left[(1-D)^{-1 / 2} \sigma^{D}(1-D)^{-1 / 2}\right]^{D}+\frac{1}{3}\left[\frac{\langle\operatorname{tr} \sigma\rangle_{+}}{1-\operatorname{trD}}+\langle\operatorname{tr} \sigma\rangle_{-}\right] . I
$$

where $\sigma$ is the stress tensor, $\sigma_{D}$ is the deviatoric stress, $D$ is a second order damage tensor, $\operatorname{tr}(X)$ is the first invariant of tensor $X$, and $\langle x\rangle_{+}$is the positive part of scalar $x$. The relationship between the effective stress and the elastic strain $\varepsilon$ is the classical elasticity isotropic relationship:

$$
\varepsilon=\frac{1+v}{E} \widetilde{\sigma}-\frac{v}{E} \operatorname{tr} \widetilde{\sigma} . I
$$

where $E$ is the Young's modulus of the material, $v$ is the Poisson's ratio, and $I$ is the second order identity tensor. The growth of damage is defined by a damage criterion:

$$
f=\hat{\varepsilon}-\frac{k_{0} \varepsilon_{r}}{(1-\operatorname{Tr}(D))\left(\varepsilon_{r}-k_{0}\right)-k_{0}}, \text { with } \hat{\varepsilon}=\sqrt{a\left(\varepsilon^{+}: \varepsilon^{+}\right)+\frac{1-a}{(1-2 v)^{2}}\left(\langle\operatorname{Tr} \varepsilon\rangle^{+}\right)^{2}}
$$
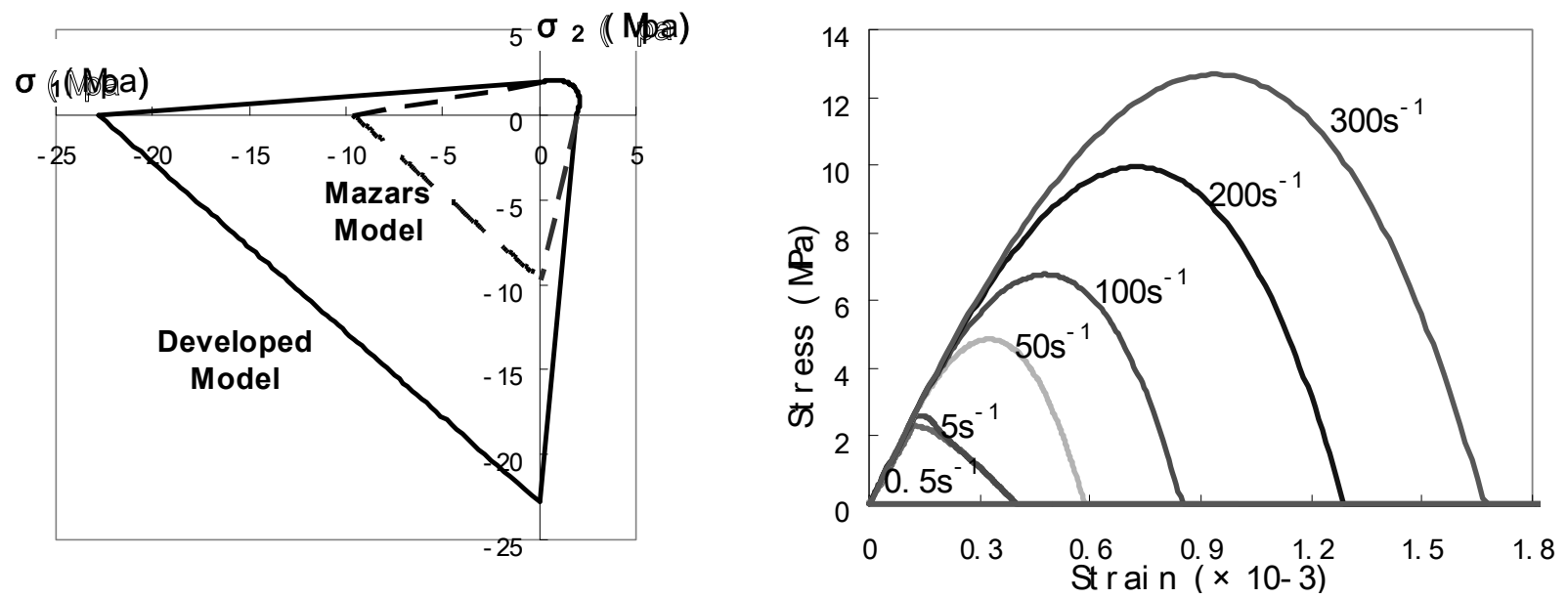

Figure 8. a) elasticity limit surface; b) stress-strain curves for concrete at different loading rates 
Parameters $\varepsilon_{r}$ and $k_{0}$ are material parameters which represents the elasticity limit and fracture strains in tension. The parameter $a$ is used to adjust the ratio between the tensile and compressive strength. An example of elasticity limit surface is plotted at Figure 8a).

When $f \leq 0$ elasticity is used, the effective stress is computed according to Equation [7] and inserted into Equation [8]. The condition $f>0$ corresponds to damage growth. In this case, the rate dependent damage law proposed by Dubé et al. (1996) is used for each principal value of damage:

$$
\dot{D}_{i}=\dot{\lambda} \frac{\langle\varepsilon\rangle^{2}}{\hat{\varepsilon}^{2}}, \quad \dot{\lambda}=\frac{1}{M}\left\langle\frac{f}{k_{0}}\right\rangle^{n}
$$

$M$ and $n$ are the model parameters that control the rate dependent effect on damage growth. An example of monotonic stress-strain relation for concrete in tension at different loading rates is plotted in Figure 8b). The material parameters describing quasi-static behaviour of concrete are: $E=19.3 \mathrm{GPa}, v=0.2, \mathrm{k}_{0}=110^{-4}$, $\varepsilon_{r}=810^{-4}, G_{f}=100 \mathrm{~J} / \mathrm{m}^{2}$. The stress strain diagram in uniaxial tension is adjusted in order to keep this fracture energy constant upon strain and damage localisation in statics, whatever the element size. This is the classical Hillerborg type regularisation scheme. The viscous parameters are $M=110^{-5}$ and $\mathrm{n}=0.4$.

The fracture energy $\mathrm{G}_{\mathrm{f}}$ is given, in static conditions, by:

$$
\frac{G_{f}}{h}=\int_{0}^{+\infty} \sigma d \varepsilon
$$

with $h$ the element size. By combining Equation [8], Equation [9] and Equation [11], with $\varphi=\frac{\varepsilon_{r}}{\kappa_{0}}$ the fracture energy $G_{f}$ is expressed as follows:

$$
\frac{G_{f}}{h}=9 E k_{0}^{2} \frac{\left(440 \varphi^{3}-440 \varphi^{2}\right) \log \left(\frac{4}{11 \varphi-11}\right)+605 \varphi^{4}-1210 \varphi^{3}+525 \varphi^{2}}{7986 \varphi^{3}-32670 \varphi^{2}+44550 \varphi-20250}
$$

\subsection{Simulation of the experiment}

The Finite Element mesh used is shown in Figure 9. A quarter of the specimen was meshed using symmetry conditions in order to reduce the computation time. The tank and specimen dimensions are provided in Figure 10. The mechanical properties of mortar are listed in Table 1. 


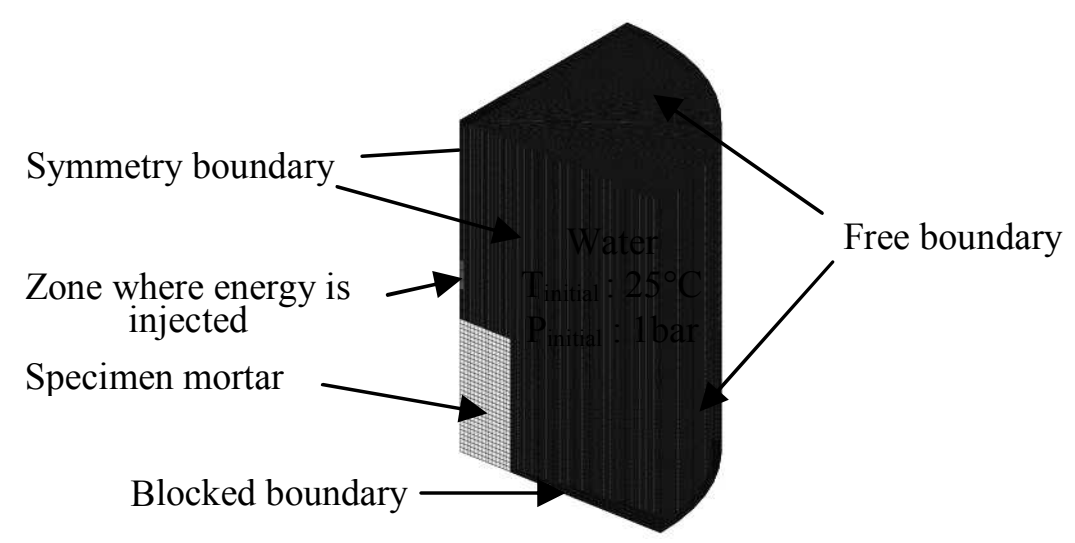

Figure 9. Finite element mesh of the simulation

\subsubsection{Distributions of damage}

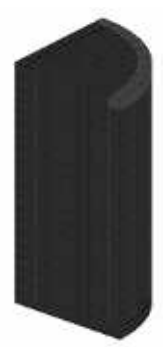

a)

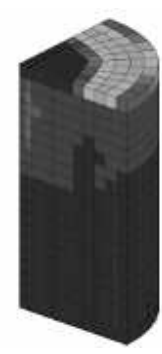

b)

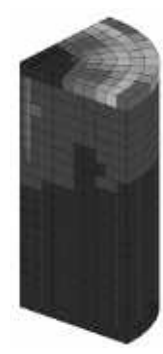

c)

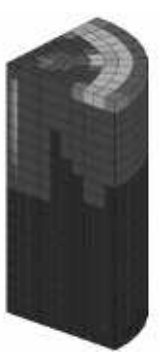

d)

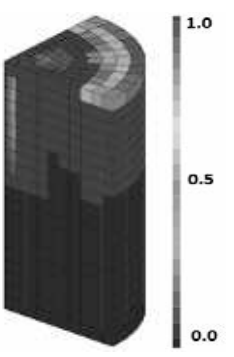

e)

Figure 10. Radial damage at different pressure levels in specimen: a) 28MPa; b) $79 \mathrm{MPa}$; c) $105 \mathrm{MPa}$; d) $193 \mathrm{MPa}$; e) $216 \mathrm{MPa}$

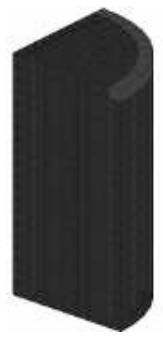

a)

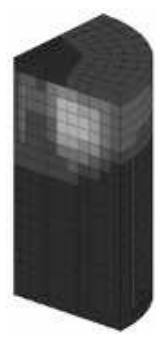

b)

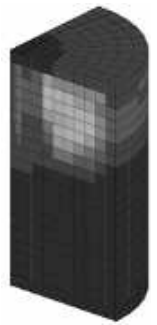

c)

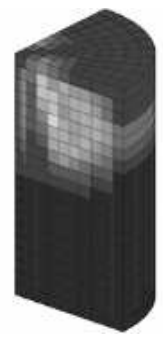

d)

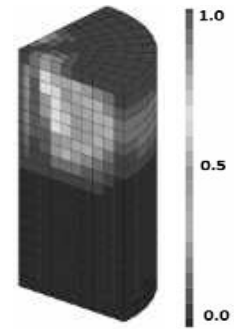

e)

Figure 11. Tangential damage at different pressure levels in specimen: a) $28 \mathrm{MPa}$; b) $79 \mathrm{MPa}$; c) $105 \mathrm{MPa}$; d) $193 \mathrm{MPa}$; e) $216 \mathrm{MPa}$

The compressive pressure wave is applied to the top face of the specimen. The specimen is damaged due to extensions induced by the Poisson effect. Hence, the principal directions of damage are in a plane perpendicular to the longitudinal 
loading direction. Radial, tangential and vertical damage at different pressure levels are presented in Figures 10-12. Damage evolves with the peak pressure. The radial and orthoradial damage values are greater than vertical damage which is related to the Poisson effect as in the above description.

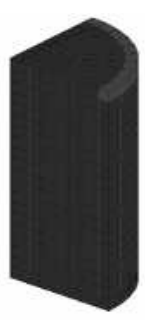

a)

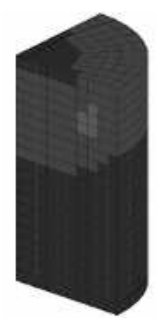

b)

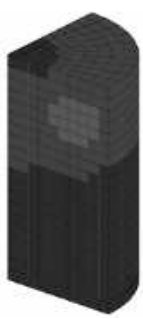

c)

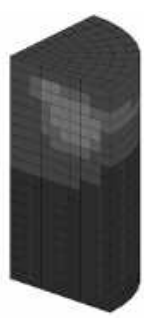

d)

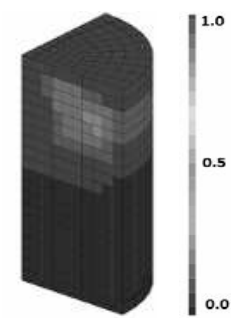

e)

Figure 12. Vertical damage at different pressure levels in specimen: a) $28 \mathrm{MPa}$; b) $79 \mathrm{MPa}$; c) $105 \mathrm{MPa}$; d) $193 \mathrm{MPa}$; e) $216 \mathrm{MPa}$

Figure 13 presents the comparison between X-Ray tomography scans and the value of principal numerical damage which is the same in a plane perpendicular to the direction of loading. In the X-Ray scans, the higher the density, the darker the colour. In Figure 13b, damage appears symmetrically at the top part of the specimen, which corresponds to the evolution of microcracking at Figure 13a.
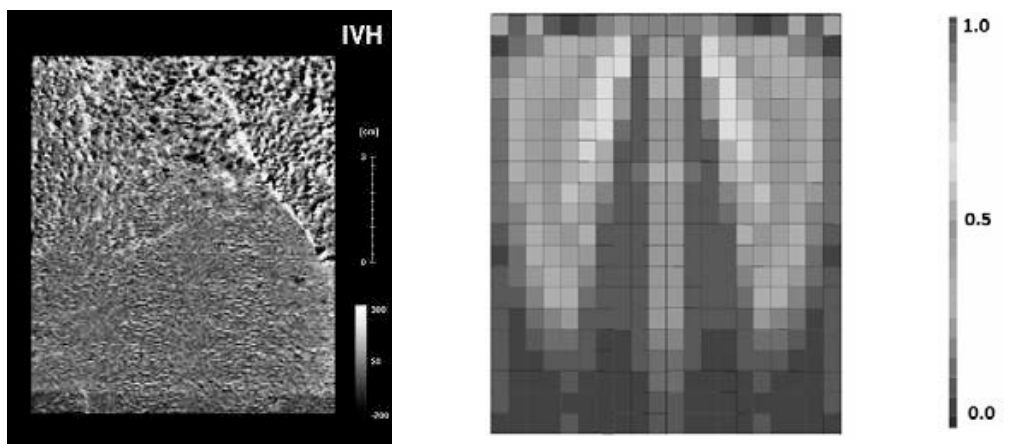

Figure 13. a) vertical cross tomography scans of specimen submitted to one shock under $250 \mathrm{MPa}$; b) principal damage of specimen under $216 \mathrm{MPa}$

\subsubsection{Evolution of permeability}

The correlation between the material intrinsic permeability and scalar damage has been reported in several works (see e.g. Picandet et al. (2002) or Choinska et al. (2007)). In the framework of anisotropic damage, the correlation needs to be reconsidered, as directional effect should be included in the formulation. In the coordinate system corresponding to the principal axes of damage, damage growth in one direction generates an increase of permeability in the two perpendicular directions. 
Hence, the permeability in one direction corresponds to contributions of the two orthogonal principal values of damage. In the present study, we consider that the relationship between principal damage and permeability is unique and that in one direction (corresponding to a given principal direction of damage), the permeability is the maximum between the two permeabilities computed according to the two orthogonal principal damage values. The relationship between permeability and damage is the one used by Jason et al. (2007):

$$
\begin{array}{ll}
K_{i}=K_{0} \cdot 10^{\left(C \cdot\left(\operatorname{Max}\left(D_{j}, D_{k}\right)-D_{0}\right)\right)} & \text { if } \operatorname{Max}\left(D_{j}, D_{k}\right)-D_{0}>0 \\
K_{i}=K_{0} & \text { if } \operatorname{Max}\left(D_{j}, D_{k}\right)-D_{0} \leq 0
\end{array}
$$

where $K_{0}$ is the permeability of the undamaged material, $D_{0}$ is the threshold of damage above which permeability starts to grow and $C$ is a model parameter. The values of model parameters $\left(C\right.$ and $\left.D_{0}\right)$ were adopted according to Jason et al. (2007).

Same as in the experimental measurement of permeability to nitrogen, the calculation of an apparent permeability was carried out on cylindrical specimens (100 mm diameter and $50 \mathrm{~mm}$ height) sawn from tested mortars cylinders. Figure 14 shows the variations of permeability according to the numerical and experimental results. The good correlation results from the fit between the experimental and numerical results.

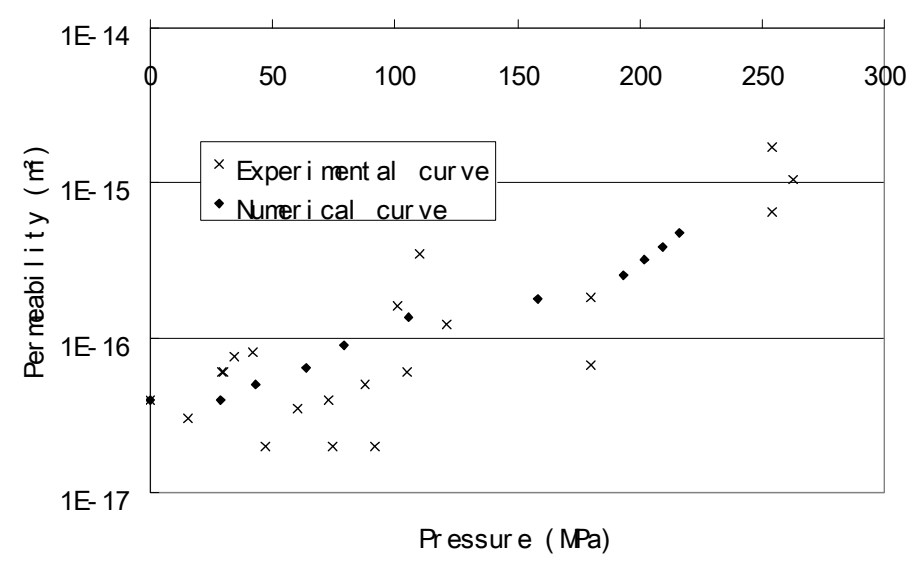

Figure 14. Comparison of the experimental and the numerical permeability as a function of the amplitude of the pressure wave

\section{Conclusion}

This paper deals with the development of a computational model for the simulation of the experiments reported earlier by Maurel et al. (2010) on the effect of PAED on damage and permeability of mortar specimens. The computational model implemented in the EUROPLEXUS software is based on a diphasic description of water, in which the electrical discharge is modelled by an increase of energy in a small region between 
the electrodes. The computational model describing the mechanical effect of PAED has been calibrated from separate experiments using the same set-up.

Mortar is modelled with an anisotropic, rate dependent, damage constitutive relation that account for crack closure. The growth of permeability due to anisotropic damage is also introduced. It is observed numerically that damage evolves with the amplitude of the shock waves. The computational results are consistent with experimental data obtained by X-Ray scans. The evolution of apparent permeability of mortar specimen is also consistent with the experimental observations.

Acknowledgement

Financial support from Total Exploration Production within the Tight Gas Reservoir Project is gratefully acknowledged.

\section{References}

Abrams D.A., "Effect of rate of application load on the compressive strength of concrete", Proceedings, ASTM 17, Part 2, 1917, p. 146-165.

Birkimer D.L., Lindemann R., "Dynamic tensile strength of concrete materials". ACI Journal, Proceedings, 1971, p. 47-49.

Choinska M., Khelidj A., Chatzigeorgiou G., Pijaudier-Cabot G., "Effects and interactions of temperature and stress-level related damage on permeability of concrete", Cement and Concrete Research, vol. 37, 2007, p. 79-88.

Casadei F., Potapov S., "Permanant fluid-structure interaction with non-conforming interfaces in fast transient dynamics", Comput. Methods Appl. Mech. Engrg, vol. 193, 2004, p. 4157-4194.

Casadei F., "Fast transient fluid-structure interaction with failure and fragmentation", $8^{\text {th }}$ World Congress on computational mechanics (WCCM8), $5^{\text {th }}$ European congress on computational methods in applied sciences and engineering (ECCOMAS 2008), June 30July 5, 2008, Venice, Italy.

Cao J., Chung D.D.L., "Defect dynamics and damage of concrete under repeated compression, studied by electrical resistance measurement", Cement and Concrete Research, vol. 31, 2001a, p. 1639-1642.

Cao J., Chung D.D.L., "Minor damage of cement mortar during cyclic compression, monitored by electrical resistivity measurement". Cement and Concrete Research, vol. 32, 2001b, p. 1656-1662.

Chambart M., Endommagement anisotrope et comportement dynamique des structures en béton armé jusqu'à la ruine, Thèse de doctorat de l'école normale supérieure de Cachan, 2009.

Desmorat R., Gatuingt F., Ragueneau F., "Nonlocal anisotropic damage model and related computational aspects for quasi-brittle materials", Engineering Fracture Mechanics, vol. 74, 2007, p. 1539-1560. 
Dubé J.F., Pijaudier-cabot G., Laborderie C., "A rate dependent damage model for concrete in dynamics", J. of Engrg. Mech. ASCE, vol. 122, 1996, p. 939-949.

Gatuingt F., Pijaudier-Cabot G., "Coupled damage and plasticity modelling in transient dynamic analysis of concrete", Int. J. Num. Anal. Meth. In Geomechanics, vol. 26, 2002, p. 1-24.

Hearn N., Lok B., "Measurement of permeability under uniaxial compression - A test method", ACI Mater. J., vol. 95, n 6, 1998, p. 691-694.

Jason L., Pijaudier-cabot G., Ghavamian S., Huerta A., "Hydraulic behaviour of a representative structural volume for containment buildings", Nuclear Engrg. and Design, vol. 237,2007 , p. 1259-1274.

Kermani A., "Permeability of stressed concrete", Build. Res. Inf., vol. 19, n 6, 1991, p. 360-366.

Lepareux M., Programme PLEXUS matériau eau modèle homogène équilibre, Rapport DMT 94/398, 1994.

Lepareux M., "Explosions des mélanges de fluides”, Cours IPSI, 2000.

Maurel O., Reess T., Matallah M., De Ferron A., Chen W., La Borderie C., Pijaudier-Cabot G., Jacques A., Rey-Bethbeder F., "Electrohydraulic shock wave generation as a means to increase intrinsic permeability of mortar", Cement and Concrete Research, vol. 40, 2010, p. 1631-1638.

Potapov S., Galon P., "Modelling of Aquitaine II pipe whipping test with the EUROPLEXUS fast dynamics code", Nuclear Engineering and Design, 235, 2005, p.2045-2054.

Pedersen R.R., Simone A., Sluys L.J., "An analysis of dynamic fracture in concrete with a continuum visco-elastic visco-plastic damage model", Engineering Fracture Mechanics, 2008, p. 3782-3805.

Picandet V., Khelidj A., Bastian G., "Effect of axial compressive damage on gas permeability of ordinary and high-performance concrete“, Cement and Concrete Research, vol. 31, 2001, p. 1525-1532.

Robbe M.F., Lepareux M., Cariou Y., "Numerical interpretation of the MARA 8 experiment simulating a hypothetical core disruptive accident", Nuclear Engineering and Design, vol. 220, 2003, p. 119-158.

Robbe M.F., Casadei F., "Comparison of various models for the simulation of a Core Disruptive Accident in the MARA 10 mock-up", Nuclear Engineering and Design, vol. 232, 2004, p. 301-326.

Robbe M.F., Lepareux M., Seinturier E., "Computation of a core disruptive accident in the MARS mock-up", Nuclear Engineering and Design, vol. 235, 2005, p. 1403-1440.

Touya G., "Contribution à l'étude expérimentale des décharges électriques dans l'eau et des ondes de pression associées, Réalisation d'un prototype industriel de 100kJ POUR le traitement de déchets par puissances électriques pulsées", Thèse de l'Université de Pau et des Pays de l'Adour, France, 2003.

Touya G., Reess T., Pécastaing L., Gibert A., Domens P., "Development of subsonic electrical discharges in water and measurements of the associated pressure waves", Journal of Physics: Applied Physics, 2006, p. 5236-5244. 